\title{
UK medical students' perceptions, attitudes, and interest toward medical leadership and clinician
} managers

This article was published in the following Dove Press journal:

Advances in Medical Education and Practice

\author{
Maral J Rouhani' \\ Eleanor J Burleigh ${ }^{2}$ \\ Chloe Hobbis ${ }^{2}$ \\ Charlotte Dunford' \\ Nadir I Osman ${ }^{3}$ \\ Christine Gan' \\ Norma B Gibbons' \\ Hashim U Ahmed ${ }^{1,4}$ \\ Saiful Miah ${ }^{1,5}$ \\ 'Department of Urology, Imperial \\ College Healthcare NHS Trust, \\ Charing Cross Hospital, London, \\ UK; ${ }^{2}$ Medical School, University of \\ Sheffield, Sheffield, UK; ${ }^{3}$ Department \\ of Urology, Royal Hallamshire \\ Hospital, Sheffield, UK; ${ }^{4}$ Division of \\ Surgery, Department of Surgery and \\ Cancer, Imperial College London, \\ London, UK; ${ }^{5}$ Division of Surgery and \\ Interventional Science, University \\ College London, London, UK
}

Background: We aimed to determine UK medical students' perceptions and attitudes and interest toward medical leadership and clinician managers.

Methods: A cross-sectional study was conducted during the academic year 2015-2016. An online questionnaire was distributed to 2,349 final-year students from 10 UK medical schools. Participants were asked to complete a 5-point Likert scale on their current perceptions, attitudes, and interest toward medical leadership and clinician managers. They were also asked to self-rate their leadership competences set by the Medical Leadership Competency Framework and to rate the quality of management and leadership training they received from their medical school. Results: In total, we received 114 complete responses. Only $7.9 \%$ of respondents were in agreement (strongly agree or agree) when asked whether they felt they were well informed about what a managerial position in medicine entails. When asked whether clinicians should influence managerial decisions within a clinical setting, $94.7 \%$ of respondents were in agreement with the statement. About $85 \%$ of respondents were in agreement that it is important for clinicians to have managerial or leadership responsibilities, with $63.2 \%$ of students in agreement that they would have liked more management or leadership training during medical school. Over half the respondents rated their management and leadership training they received during medical school as "very poor" or "poor" (54.4\%).

Conclusion: Our study suggests that UK medical students have an appetite for management and leadership training and appreciate its importance but feel that the training they are receiving is poor. This suggests that there is a gap between the demand for management and leadership training and the quality of training supplied by UK medical schools.

Keywords: medical leadership, clinician managers, medical student, training

\section{Introduction}

The principal objective of medical management requires the manager to organize health care staff in a manner that optimally achieves targets and goals. Leadership is the ability to determine how others act and interact. Medical leadership requires the setting of a direction which is then followed by inspiring and motivating other health care professionals to embrace it. Globally, there has been a recent drive for more clinicians to step into management and leadership roles within health care settings with the aim to close the gap and barrier between clinicians and managers.

The majority of UK hospital Chief Executive Officers do not have a formal clinical background. ${ }^{2}$ Health care is a diverse, complex, and unpredictable field which is often best appreciated and understood by clinicians who have direct hands-on experience of patient care. ${ }^{3}$ There is mounting evidence that those making managerial decisions 
within a clinical setting should possess clinical, managerial, and leadership skills., ${ }^{4,5}$ A strong favorable association has been shown between clinician Chief Executive Officers and the quality of a hospital resulting in positive implications on financial resources, quality of care provided, and hospital social performance. ${ }^{4,5}$ The delivery of a greater number of clinician managers would require doctors to be given the opportunity to obtain leadership and managerial skills alongside their clinical training and commitments. ${ }^{1}$

In the UK, the Medical Leadership Competency Framework (MLCF) was launched in 2008 by the Academy of Medical Royal Colleges and the National Health Service (NHS) Institute for Innovation and Improvement. It outlined the management and leadership competencies required by doctors, dentists, and medical students in order to become more involved in the planning, delivery, and evolution of health services across the NHS. ${ }^{6}$ The framework is based upon 5 domains in which a doctor must be competent in order to deliver appropriate, safe, and effective services.

- Demonstrating personal qualities

- Working with others

- Managing services

- Improving services

- Setting direction

The NHS is continuing to evolve and expand, and the need for a strong cohort of managers and leaders is arguably more imperative than ever. When leadership has been compromised in hospitals and practices, a decline in patient care has been witnessed. ${ }^{1}$ Independent enquiries into such failing hospitals have clearly demonstrated that a lack of leadership and management were key components that resulted in continuous adverse patient care and outcomes. ${ }^{7,8}$

Within the UK health system, only $5 \%$ of senior managers have a clinical background, and this is in contrast to the USA, where it is $30 \%{ }^{1}$ The UK is currently addressing this issue with the introduction of the MLCF and the Darzi Fellowship programmed both of which promote, train, and mentor clinicians into senior management positions. ${ }^{9}$

The MLCF first described management and leadership competences in 2008, and the General Medical Council provided a curriculum guide intended for utilization by UK medical schools the following year. ${ }^{10,11}$ Since these publications, no study has yet to report the current perceptions and attitudes of UK medical students to the concept of "Clinician Managers," and the interest levels of current UK medical students in pursuing clinical managerial and leadership roles in their future careers. Here, we provide a contemporary analysis to answer these questions.

\section{Methods Study design}

We performed a descriptive cross-sectional study during the academic year 2015-2016. Our defined population consisted of final-year students in UK medical schools.

\section{Participants}

All final-year students (academic year of 2015-2016) from 10 UK medical schools (Sheffield, Aberdeen, Nottingham, Norwich, Cardiff, Warwick, Bristol, Keele, Edinburgh, and Manchester $[n=2,349])$ were invited to complete an online questionnaire.

The study was approved by the University of Sheffield Medical School ethics committee (006226). The informed content of the study explained to participants the study's nature, format, and the reasons behind the study. Completion of the questionnaire was deemed to be consent to participate in the study. Study participants were made aware that the collected data was intended for publication and presentation. Ethical issues with regard to data security were addressed by using a secure cloud-based access system.

\section{Data collection method}

The methods are reported in accordance with the Checklist for Reporting Results of Internet Surveys. ${ }^{12}$ The instrument used in our study was an 18-item questionnaire. As no existing instrument was validated to evaluate our study aims, the questions were developed based on literature review and previously published articles in peer-reviewed journals assessing the attitudes of medical students toward medical leadership and the adequacy of this subject in their medical curricula. ${ }^{13-20}$ We first piloted our study in our home institution (University of Sheffield) to ensure face validity and clarity. ${ }^{21}$

The 18-item questionnaire was created using an online survey tool and sent to an academic or institutional contact within each medical school. These individual questionnaires were distributed via a weblink to the relevant parties. Anonymous responses were completed on this online survey tool. Questions 1-7 used a 5-point Likert scale (1: strongly agree, 2: agree, 3: neither agree or disagree, 4: disagree; and 5: strongly disagree) to assess final-year medical students' perceptions, attitudes, and interest toward medical leadership and clinician managers. Questions 8-17 asked the respondents to rate themselves on a 5-point Likert scale (1: very 
good, 2: good, 3: satisfactory, 4: poor; and 5: very poor) on 10 personal qualities deemed important by the MLCF in leadership competence (confidence, organization, time-keeping, motivating others, calm under stress, resolving conflict, communication, self-reflection, acting with integrity, and critical evaluation). Question 18 used a 5-point Likert scale (1: very good, 2: good, 3: satisfactory, 4: poor; and 5: very poor) to rate the respondents' evaluation of the management and leadership training provided by their medical school.

\section{Data analysis}

Questionnaire responses were entered into an SPSS database (SPSS Statistics Version 2.1, SPSS Inc., Chicago, IL, USA).

\section{Results}

In total, we received 114 complete responses from final-year medical students from the 10 selected UK medical schools (response rate $=4.9 \%[114 / 2,349]$, Sheffield $=27$, Aberdeen $=26$, Nottingham $=24$, Norwich $=2$, Cardiff $=3$, Warwick $=2$, Bristol =13, Keele =8, Edinburgh =4, and Manchester =5) All results are summarized in Tables 1-3.

\section{Questions 1-7: perceptions, attitudes, and interest toward medical leadership and clinician managers}

Only $7.9 \%$ of respondents were in agreement (strongly agree or agree) when asked whether they felt they were well informed about what a managerial position in medicine entails, with $54.4 \%$ and $30.7 \%$ of respondents disagreeing and strongly disagreeing, respectively, with this statement.
When asked whether clinicians should influence managerial decisions within a clinical setting, $94.7 \%$ of respondents were in agreement with the statement, with one respondent out of $114(0.9 \%)$ disagreeing. Similarly, $85 \%$ of respondents were in agreement that it is important for clinicians to have managerial or leadership responsibilities, with $63.2 \%$ of students in agreement that they would have liked more management or leadership training during medical school.

The questions of seeking additional leadership or management training in postgraduate study and whether final-year medical students were interested in taking on leadership or managerial responsibilities during their careers resulted in majority agreement at $59.7 \%$ and $65.8 \%$, respectively. Finally, $78 \%$ of students were in agreement that managerial or leadership opportunities should be highlighted and promoted to medical students (Table 1).

\section{Questions 8-17: self-perception of leadership skills}

Reponses for each quality were most frequently "very good" or "good." The highest ranked quality was "acting with integrity", with 93.8\% students rating themselves "very good" or "good" and no students rating themselves as "poor" or "very poor."

Organization and motivating others were also highranked qualities among the medical students, with $77.2 \%$ and $76.3 \%$, respectively, rating themselves as either "very good" or "good."

Confidence and keeping calm under stress had the widest range of responses, with the lowest overall positive ratings

Table I Perceptions, attitudes, and interest toward medical leadership and clinician managers using a 5-point Likert scale (strongly agree to strongly disagree)

\begin{tabular}{|c|c|c|c|c|c|}
\hline Statement & $\begin{array}{l}\text { Strongly } \\
\text { agree } \\
(\%)\end{array}$ & $\begin{array}{l}\text { Agree } \\
(\%)\end{array}$ & $\begin{array}{l}\text { Neither agree } \\
\text { or disagree } \\
\text { (\%) }\end{array}$ & $\begin{array}{l}\text { Disagree } \\
\text { (\%) }\end{array}$ & $\begin{array}{l}\text { Strongly } \\
\text { disagree } \\
(\%)\end{array}$ \\
\hline I am well informed about what a managerial position in medicine entails & 1.8 & 6.1 & 7.0 & 54.4 & 30.7 \\
\hline $\begin{array}{l}\text { I think managerial decisions within a clinical setting should be } \\
\text { influenced by clinicians }\end{array}$ & 65.8 & 28.9 & 4.4 & 0.0 & 0.9 \\
\hline $\begin{array}{l}\text { I think it is important for clinicians to have managerial/leadership } \\
\text { responsibilities }\end{array}$ & 37.2 & 47.8 & 12.4 & 2.7 & 0.0 \\
\hline $\begin{array}{l}\text { I would like to have had more management/leadership training during } \\
\text { medical school }\end{array}$ & 23.7 & 39.5 & 23.7 & 13.2 & 0.0 \\
\hline $\begin{array}{l}\text { I would seek additional leadership/management training in my } \\
\text { postgraduate studies }\end{array}$ & 20.2 & 39.5 & 21.1 & 17.5 & 1.8 \\
\hline $\begin{array}{l}\text { I am interested in taking on leadership/managerial responsibilities } \\
\text { during my career }\end{array}$ & 21.9 & 43.9 & 21.9 & 9.6 & 2.6 \\
\hline $\begin{array}{l}\text { I think clinicians' managerial/leadership opportunities should be } \\
\text { highlighted and promoted to medical students }\end{array}$ & 25.4 & 52.6 & 16.7 & 5.3 & 0.0 \\
\hline
\end{tabular}


Table 2 Self-perception of leadership skills highlighted by the MLCF, using a 5-point Likert scale (very good to very poor)

\begin{tabular}{llllll}
\hline Leadership skill & $\begin{array}{l}\text { Very good } \\
\text { (\%) }\end{array}$ & $\begin{array}{l}\text { Good } \\
\text { (\%) }\end{array}$ & $\begin{array}{l}\text { Satisfactory } \\
\text { (\%) }\end{array}$ & $\begin{array}{l}\text { Poor } \\
\text { (\%) }\end{array}$ & $\begin{array}{l}\text { Very poor } \\
\text { (\%) }\end{array}$ \\
\hline Confidence & 22.1 & 43.4 & 26.5 & 8.0 & 0.0 \\
Organization & 36.8 & 40.4 & 16.7 & 6.1 & 0.0 \\
Time-keeping & 29.8 & 37.7 & 23.7 & 7.9 & 0.9 \\
Motivating others & 17.5 & 58.8 & 20.2 & 3.5 & 0.0 \\
Keeping calm under stress & 17.5 & 48.2 & 26.3 & 7.9 & 0.0 \\
Resolving conflict & 15.8 & 54.4 & 21.9 & 2.9 & 0.0 \\
Communicating ideas & 22.8 & 52.6 & 21.9 & 2.6 & 0.0 \\
Self-reflection & 24.6 & 44.7 & 24.6 & 6.1 & 0.0 \\
Acting with integrity & 51.3 & 42.5 & 6.2 & 0.0 & 0.0 \\
Critical evaluation & 14.0 & 55.3 & 24.6 & 6.1 & 0.0 \\
\hline
\end{tabular}

Abbreviation: MLCF, Medical Leadership Competency Framework.

Table 3 Perception of management and leadership training during medical school using a 5-point Likert scale (very good to very poor)

\begin{tabular}{llllll}
\hline & $\begin{array}{l}\text { Very } \\
\text { good } \\
(\%)\end{array}$ & $\begin{array}{l}\text { Good } \\
(\%)\end{array}$ & $\begin{array}{l}\text { Satisfactory } \\
(\%)\end{array}$ & $\begin{array}{l}\text { Poor } \\
(\%)\end{array}$ & $\begin{array}{l}\text { Very } \\
\text { poor } \\
(\%)\end{array}$ \\
\hline Training received & 0.0 & 9.6 & 36.0 & 43.9 & 10.5 \\
\hline
\end{tabular}

(65.5\% and 65.8\%, respectively, for "very good" or "good" responses) (Table 2).

\section{Question 18: leadership training during medical school}

Our last question asked final-year medical students to rate their management and leadership training during medical school. Over half the respondents rated their training as "very poor" or "poor" (54.4\%). None rated their training as "very good" and 11 students (9.6\%) rated it as "good" (Table 3 and Figure 1).

\section{Discussion}

This is the first multi-institutional study that has assessed the attitudes and views of medical students toward medical leadership and the concept of "Clinician Managers" following the MCLF recommendation that all management and leadership competencies should be reached at an undergraduate level.

The findings of this survey demonstrate that medical students possess an interest in managerial and leadership roles, with $78 \%$ agreeing that these disciplines should be promoted to medical students. In contrast, over $85 \%$ of those surveyed felt they were not well informed about what a managerial position in medicine entails. This mirrors a report by the UK General Medical Council in which it was reported that 1 in 10 graduates felt inadequately prepared for practice, with core leadership and management competencies as key areas of concern. ${ }^{22}$

Over $63 \%$ of our cohort felt that they would have liked more leadership training in medical school, and over half of those surveyed rated their experience of leadership training during medical school as poor. A recent study by Quince et $\mathrm{al}^{23}$ used focus group discussions to explore medical students' attitudes toward leadership and management education in the undergraduate curriculum. Two main themes emerged: the need to make leadership and management education relevant in the clinical context and the need for students to understand the broad perspective of patients and other stakeholders involved in health care provision. Structured observation, reflection, critical appraisal, and analysis of mistakes were some of the suggested methods of integration into the medical undergraduate curriculum. In parallel with our findings, Quince et $\mathrm{al}^{23}$ concluded that medical students were perhaps more open to the prospect of undergraduate leadership and management education than previously thought.

A systematic review of attitudes of medical students to leadership and management by Abbas et $\mathrm{al}^{24}$ in 2011 also demonstrated that there is a desire among medical students for the need for more leadership and management training. However, lack of curriculum time and disinterest were identified as key barriers to such initiatives. Our study suggests that the desire for more training in these fields still remains strong among a more contemporary cohort of medical students; however, these educational aspirations are still potentially yet to be catered for.

There is a general consensus that leadership training should be incorporated into medical training of doctors; therefore, different methods to implement this must be addressed. ${ }^{25}$ Hadley et $\mathrm{al}^{9}$ considered whether formative assessment is a useful approach in developing the leadership 


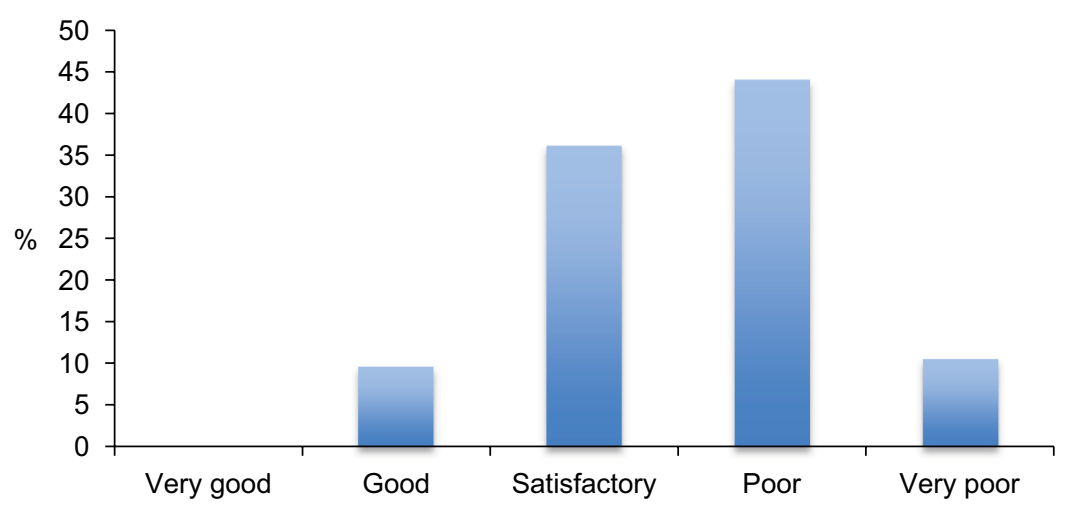

Figure I All evaluation of management and leadership training received during medical school by final-year medical students.

skills of junior doctors and found that over $60 \%$ of those surveyed felt their leadership skills had improved as a result of feedback received. Such an approach could be transferrable to medical students. Another method of improving leadership training during medical school is a formal leadership course which has been shown to be beneficial and has a high postcourse satisfaction rating by medical students. ${ }^{26}$

Our study has also suggested that despite seemingly poor management and leadership training at medical school, students rated themselves highly on the ten personal qualities outlined by the MLCF. Whittle and Eaton ${ }^{18}$ found a similar phenomenon when surveying first-year students on named transferable skills for medicine, with very few students reporting that they were below average in any skills. This suggests that, while students feel their level of training is inadequate, their management and leadership skills are being developed through other means or were preexisting qualities prior to attending medical school.

\section{Limitations}

There are several limitations inherent to this study. All medical schools were invited to take part in our study; however, only 10 out of the 32 UK medical schools agreed. Our sample size of 114 may not represent the population for which the scale was intended, and there is a potential that our results may be subject to the influence of chance factors. Our study is also limited by the low response rate $(114 / 2,349$ [4.9\%]), which could have been addressed with a second wave of emails or providing paper-based questionnaires.

Our study had a superior number of participants compared to the majority of previous studies and sampled a greater number of institutions. ${ }^{13-20}$ Nevertheless, further studies should include a greater participant number from a more inclusive cohort of medical schools.

\section{Conclusion}

It has now nearly been a decade since MCLF recommended that all management and leadership competencies should be reached at an undergraduate level and that the undergraduate medical curricula must facilitate this. Our study suggests that UK medical students have an appetite for management and leadership training and appreciate its importance but feel that the training they are receiving is poor. This suggests that there is a gap between the demand for management and leadership training and the quality of training supplied by UK medical schools.

\section{Availability of data and material}

All raw data is available on a cloud-based access system.

\section{Author contributions}

SM and NIO designed the idea for this manuscript. EJB and $\mathrm{CH}$ acquired the data for this work. $\mathrm{CD}, \mathrm{NIO}, \mathrm{CG}, \mathrm{NBG}$, HUA, and SM interpreted and analyzed the data. MJR, EJB, $\mathrm{CH}, \mathrm{CD}, \mathrm{NIO}, \mathrm{CG}, \mathrm{NBG}, \mathrm{HUA}$, and SM drafted the work and revised it critically. All authors contributed toward data analysis, drafting and revising the paper and agree to be accountable for all aspects of the work.

\section{Disclosure}

The authors report no conflicts of interest in this work.

\section{References}

1. Warren OJ, Carnall R. Medical leadership: why it's important, what is required, and how we develop it. Postgrad Med J. 2011;87(1023):27-32.

2. Darzi A. A time for revolutions - the role of clinicians in health care reform. $N$ Engl J Med. 2009;361(6):e8.

3. Abbasi K. Clinician managers: back in vogue. J R Soc Med. 2017; 110(1):3.

4. Goodall AH. Physician-leaders and hospital performance: is there an association? Soc Sci Med. 2011;73(4):535-539.

5. Sarto F, Veronesi G. Clinical leadership and hospital performance: assessing the evidence base. BMC Health Serv Res. 2016;16(Suppl 2):169.

6. Swanwick T, McKimm J. What is clinical leadership...and why is it important? Clin Teach. 2011;8(1):22-26. 
7. Berwick D. A Promise to Learn-A Commitment to Act: Improving the Safety of Patients in England. London: Department of Health; 2013.

8. Francis R. Report of the Mid Staffordshire NHS Foundation Trust Public Inquiry. London: The Stationary Office; 2013.

9. Hadley L, Black D, Welch J, Reynolds P, Penlington C. Encouraging formative assessments of leadership for foundation doctors. Clin Teach. 2015;12(4):231-235.

10. Medical Leadership Competency Framework. Enhancing Engagement in Medical Leadership Project. NHS Institute for Innovation and Improvement and Academy of Medical Royal Colleges; 2008.

11. Tomorrow's Doctors. Outcomes and standards for undergraduate medical education. General Medical Council; 2009.

12. Eysenbach G. Improving the quality of web surveys: the Checklist for Reporting Results of Internet E-Surveys (CHERRIES). J Med Internet Res. 2004;6(3):e34.

13. Mazor KM, Campbell EG, Field T, et al. Managed care education: what medical students are telling us. Acad Med. 2002;77(11):1128-1133.

14. Noritz GH. Medical students and managed care: one school's experience. Med Health R I. 1997;80(2):57-60.

15. Tibbitts GM. Physician leadership. Leadership education for medical students. Physician Exec. 1996;22(9):31-34.

16. McEvoy M, O'Brien M. Undergraduate attitudes to exposure to an NHS resource allocation problem. Public Health. 1985;99(3):178-182.

17. Varkey P, Peloquin J, Reed D, Lindor K, Harris I. Leadership curriculum in undergraduate medical education: a study of student and faculty perspectives. Med Teach. 2009;31(3):244-250.
18. Whittle SR, Eaton DG. Attitudes towards transferable skills in medical undergraduates. Med Educ. 2001;35(2):148-153.

19. Carufel-Wert DA, Younkin S, Foertsch J, et al. LOCUS: immunizing medical students against the loss of professional values. Fam Med. 2007;39(5): 320-325.

20. Martins HM, Detmer DE, Rubery E. Perspectives on management education: an exploratory study of UK and Portuguese medical students. Med Teach. 2005;27(6):493-498.

21. Miah S, Pang KH, Rebello W, et al. What factors influence UK medical students' choice of foundation school? Adv Med Educ Pract. 2017;8:293-297.

22. Jagger O. Supporting and driving trainee-led leadership. Future Hosp J. 2015;2:211-217.

23. Quince T, Abbas M, Murugesu S, et al. Leadership and management in the undergraduate medical curriculum: a qualitative study of students' attitudes and opinions at one UK medical school. BMJ Open. 2014;4(6): e005353.

24. Abbas MR, Quince TA, Wood DF, Benson JA. Attitudes of medical students to medical leadership and management: a systematic review to inform curriculum development. BMC Med Educ. 2011;11:93.

25. Sonsale A, Bharamgoudar R. Equipping future doctors: incorporating management and leadership into medical curriculums in the United Kingdom. Perspect Med Educ. 2017;6(2):71-75.

26. Warde CM, Vermillion M, Uijtdehaage S. A medical student leadership course led to teamwork, advocacy, and mindfulness. Fam Med. 2014;46(6):459-462.
Advances in Medical Education and Practice

\section{Publish your work in this journal}

Advances in Medical Education and Practice is an international, peerreviewed, open access journal that aims to present and publish research on Medical Education covering medical, dental, nursing and allied health care professional education. The journal covers undergraduate education, postgraduate training and continuing medical education

\section{Dovepress}

including emerging trends and innovative models linking education, research, and health care services. The manuscript management system is completely online and includes a very quick and fair peer-review system. Visit http://www.dovepress.com/testimonials.php to read real quotes from published authors. 